Article

\title{
Spatio-Temporal Differentiation Mode and Threshold Effect of Yangtze River Delta Urban Ecological Well-Being Performance Based on Network DEA
}

\author{
Meijuan $\mathrm{Hu}^{1}$, Suleman Sarwar ${ }^{2}$ and Zaijun $\mathrm{Li}^{3, *}$ \\ 1 School of Tourism and Culinary Science, Yangzhou University, Yangzhou 225127, China; \\ humeijuan156@163.com \\ 2 Finance and Economics Department, College of Business, University of Jeddah, Jeddah 21442, Saudi Arabia; \\ ch.sulemansarwar@gmail.com \\ 3 Research Institute of Central Jiangsu Development, Yangzhou University, Yangzhou 225009, China \\ * Correspondence: junzailinyi@gmail.com
}

Citation: Hu, M.; Sarwar, S.; Li, Z. Spatio-Temporal Differentiation Mode and Threshold Effect of Yangtze River Delta Urban Ecological Well-Being Performance Based on Network DEA. Sustainability 2021, 13, 4550. https://doi.org/10.3390/ su13084550

Academic Editor: Antonio Boggia

Received: 29 March 2021

Accepted: 16 April 2021

Published: 20 April 2021

Publisher's Note: MDPI stays neutral with regard to jurisdictional claims in published maps and institutional affiliations.

Copyright: (c) 2021 by the authors. Licensee MDPI, Basel, Switzerland. This article is an open access article distributed under the terms and conditions of the Creative Commons Attribution (CC BY) license (https:/ / creativecommons.org/licenses/by/ $4.0 /)$.

\begin{abstract}
Improving ecological well-being performance (EWP) is the essential requirement of green transformation development and ecological civilization construction. With the help of a network DEA model and threshold panel regression model, this study evaluated urban ecological well-being performance to explore the evolution process, impact, and optimization path of urban ecological well-being performance in the Yangtze River Delta from 2001 to 2017. The findings are as follows: (1) The ecological well-being performance of all cities in the region had been steadily improving since 2001, most cities had realized the transformation from a low performance level to a higher performance level, and there was an obvious spatial mismatch between urban economic development level and ecological well-being performance. (2) A regional urban ecological well-being performance development mode was constantly optimized, sustainable urban development ability was improved, and the number of high-high $(\mathrm{HH})$ mode cities was gradually increasing while the number of lowlow (LL) mode cities was gradually decreasing. (3) Under the influence of threshold variables of population density, industrialization level, and environmental regulation, the impact of urbanization on ecological well-being performance had different threshold characteristics. Economic growth, industrialization, and government macro-control had significantly negative restraining effects, while consumption level, industrial structure upgrading, energy efficiency, and technological innovation had significantly positive driving effects.
\end{abstract}

Keywords: ecological well-being performance; network DEA model; spatio-temporal evolution; threshold effect; Yangtze River Delta

\section{Introduction}

Sustainable development is an important issue of global concern and a necessary requirement for building a community with a shared vision for humankind [1]. Along with the initiation of the 2030 agenda of sustainable development, the Chinese government has responded positively to calls to mobilize green, low-carbon, and sustainable development; incorporated ecological progress into an overall plan for promoting socialist modernization with Chinese characteristics; put forward the construction of beautiful China; and made a commitment to reducing carbon dioxide emissions per unit of GDP by more than $65 \%$ in 2030 and to achieving carbon neutrality by 2060 . To make green contributions for the construction of a clean and beautiful world, it is necessary to transform conventional economic growth modes into green development modes, cultivate innovative demonstration areas for sustainable development, and realize the unification of ecological economic and social benefits. The integration of the Yangtze River Delta is not only a demonstration area for regional integration and high-quality development in China, but also plays an important 
leading role in promoting the high-quality development of the Yangtze River Economic Belt. Against the background of the rapid advancement of high-quality integration in the Yangtze River Delta, the Yangtze River Delta should strive to construct an ecological and green integrated development demonstration zone and build a new development pattern featuring good ecology and happy cities. In the context of ecological civilization construction, it becomes imperative to maximize the well-being performance of ecology consumption, given the limited natural resources and ecosystem space. Hence, the analysis of regional ecological well-being performance not only provides important guidance for promoting the transformation of social and economic green development, but also provides strong support for the realization of China's green and sustainable development.

There exists mutual influence between human activities and the environment, the economic system, ecological system, and social system, which all interact with and affect each other [2-4]. Specifically, the economic system is a subsystem of the ecological systemeconomic growth serves only as an intermediary to realize the promotion of human well-being, while the ecological system is the material basis, guaranteeing the provision of services and utilities [5-8]. As Reid et al. (2005) noted, there are interacting linkages between ecosystems and human well-being, and changes in ecosystem services affected the supply of human well-being [9]. Michalos et al. (2011) and Michalos (2014) argued that human well-being is placed at the core of the circular mandala, which is surrounded by three concentric circles symbolizing different resources, where the outer environment circle encompasses and affects all of the other domains and provides ecosystem resources for sustenance [10]. Zheng et al. (2006) pointed out that changes in human well-being not only affect economic development but also influence the way the ecological system is used by altering its service functions [11]. The essence of green economic transformation and development is to maximize social well-being using the minimum amount of ecological resource consumption, and to realize the decoupling of ecological resource consumption and social well-being [12]. However, the stock of natural capital increasingly restricts the improvement of the quality of economic development and the efficiency of social services, causing economic growth to encounter bottlenecks of "ecological threshold" and "well-being threshold", successively [13,14], which betrays the ultimate goal of sustainable economic and social development that aims to increase the material and spiritual value of well-being of contemporary and future generations within the limited ecological carrying capacity [15]. Therefore, understanding how to get rid of the "well-being threshold" trap and restrict the consumption of natural capital within the scope of ecological carrying capacity requires an accurate evaluation of the utility of ecological well-being.

Ecological well-being performance (EWP) is as an important tool to measure the coordinated relations between ecological system services, environmental stress, and human well-being [16,17]. It incorporates human development evaluation on the basis of ecological efficiency, effectively connecting the three major systems of economy, society, and ecology. EWP was first expressed as UE = Service/Throughput. The ultimate efficiency of social economic services (UE) is defined as a service per unit throughput, where the service refers to the transformation from the economic and social system-that is, the well-being that humans obtain from the ecosystem - and throughput is the synthesis of low-entropy energy and material and high-entropy waste emitted by humans into the ecosystem [5]. This measurement of EWP, similar to the calculation of eco-efficiency, is considered to be the ratio of the amount of welfare value to the amount of resource consumption. Based on the core connotation of EWP, Daly [6] proposed an ecological well-being performance characterized by the value quantity of social well-being per physical quantity of ecological resource consumption. Common (2007) developed the ratio of human satisfaction to the ecological footprint to evaluate ecological well-being performance, where the environmental cost is composed of energy consumption, the ecological footprint, and greenhouse gas emissions [18]. Dietz et al. (2009) proposed the efficient human well-being relevant to resource and environmental consumption by adopting stochastic frontier production models [19]. Dietz et al. (2012) further developed the ecological intensity of human well-being (EIWB), 
defined as the environmental stress placed on human well-being (Stress/Well-being), where the stress is measured by the ecological footprint while well-being is measured through life expectancy [20]. Moreover, indicators including the Happy Planet Index (HPI) [21], the environmental efficiency of well-being (EWEP) [22], the Index of Ecological Well-being Performance (IEWP) [23], and the ratio of the Human Development Index (HDI) to carbon emissions or energy consumption [24] have been widely developed to characterize EWP. However, the ratio calculation method is easily influenced by the polarization of the denominator, and thus, both the nonparametric Data Envelopment Analysis (DEA) and Stochastic Frontier Production models are extensively employed to evaluate ecological well-being efficiency [25-28].

Spatiality is the basic attribute of geography. The first law of geography posits that everything is related to everything else, and that near things are more related than distant things [29]. Space is highly consequential in environmental and resource economic analyses [30]. Spatial effects concerning spatial dependence, heterogeneity, and clustering have been considered in eco-efficiency analysis and evaluation [31-33]. As Reid et al. (2005) pointed out, ecosystem services and human well-being have a certain spatial and temporal dependence [9]. The geographic space of well-being reflects the organic combination of function, effectiveness, and efficiency; integrates material space and relational space; and constitutes the foundation of spatial well-being [34]. It was found that there are positive spatial associations of provincial EWP, presenting obvious high-high (HH) and low-low (LL) clustering [35-37]. Similarly, the EWP showed obvious spatial autocorrelation at the city level [38]. Moreover, the EWP significantly exhibits spatial heterogeneity. The EWP of most developed countries was below the average level, while developing countries were above the average level. Some countries have achieved the well-being level by decoupling from ecological resource consumption, while the EWP of China, Brazil, and Mexico showed a continuous downward trend, with China being in the fastest decline $[5,39]$. There was also a significant gap in the EWP among eastern, central, and western provinces of China, but central and western regions had a $\beta$-convergence effect and showed a "catch-up effect" on advanced provinces [40].

The EWP is influenced by many factors related to regional culture, technology, and skills, and the organizational mode of elements and behaviors. The realization of the wellbeing effect mainly relies on the high input of natural consumption. Natural consumption factors are the "pull factors" for the improvement of well-being, and the service efficiency has an increasing "inhibitory effect" on the EWP [39]. Economic growth, as an effective means to achieve urban well-being efficiency, exhibits different influencing effects on EWP. It was found that economic growth had relatively little impact on the EWP of underdeveloped countries [41], that economic growth causing the increase in carbon emission reduced the human well-being in Central and Eastern Europe [42], that economic growth shows an "inverted U" relationship with the EWP [43], and that human well-being could be elevated by increasing health service expenditures [44]. In addition, factors such as globalization, technological innovation, urbanization, industrial structure, energy intensity, environmental regulations, energy structure, etc. had, to some degree, impacts on the improvement and optimization of EWP [45-48].

To sum up the contribution of this study: firstly, existing studies have extensively studied the measurement methods, spatial difference, and influencing factors of the EWP, which provides profound reference for constructing theoretical and empirical research framework. However, the existing studies are mostly focused on large-scale, single-level, and horizontal comparative analysis and verification. There are few systematic studies involving the spatio-temporal evolution, formation mechanisms, and development modes of urban EWP. Secondly, most studies regard the evaluation process of EWP as a "black box", ignoring the stage characteristics of the internal transformation process of EWP. Additionally, most studies adopt a single dimension index to characterize human wellbeing, which fails to accurately reflect the multidimensional facets of well-being. In the context of the high-quality development of regional integration and the construction of 
ecological civilization and happy cities, if we want to objectively grasp dynamic evolution law among human well-being, natural consumption, and economic growth in the "full world", and if we want to scientifically obtain the ideal mode and improvement direction for sustainable urban development, it is necessary to deeply investigate the internal process and intrinsic nature of the EWP, which can help provide reasonable guidance and accurate value appeals for sustainable urban development.

In view of this, the current study conducts an analysis of urban ecological well-being performance around the following questions: what are the dynamic changes and spatial structure characteristics of the overall efficiency of the EWP and its sub-stage efficiency? Is the evolution process dominated by production efficiency or service efficiency? What is the development mode? What factors affect the spatio-temporal evolution? What is the path to achieve the optimization and improvement of the EWP? Specifically, 41 cities in the Yangtze River Delta region were selected as study area on the basis of constructing the input-output indicator system and the network DEA model was used to calculate the production efficiency and service efficiency; then, the spatio-temporal evolution patterns, development modes, and formation mechanisms of urban EWP were analyzed.

The paper is organized as follows: Section 2 introduces the theoretical framework, methods, and data source. Section 3 summarizes the results, including the spatio-temporal evolution characteristics, coupling mode, and influencing factors of ecological well-being. The final section contains the conclusion and policy recommendations of the study.

\section{Framework, Methods, Index System and Data}

\subsection{Theoretical Framework}

Based on sustainable development economics, ecological economics, environmental geography, and other related theories, by referring to related ecological well-being studies and according to the perspective of the functions and needs of urban social development, this study mainly evaluates the level of urban comprehensive well-being level and function realization status from three dimensions of economy, society, and environment. The ecosystem is the source of human well-being, providing humans with water, energy, land, and other primitive production and living materials. Through a series of links such as production, processing, distribution, and consumption, natural resources can be transformed into economic material wealth to realize the accumulation of artificial capital. Moreover, the ecosystem is also the material carrier for human survival and life, providing direct ecological services such as fresh air, clean water, beautiful scenery, pleasant climate, and environmental quality, which satisfy the green well-being needs of humans. The utility services and social services generated by economic material wealth are indirect services, which are called economic well-being and social well-being, respectively, and both of them belong to material well-being. The specific evaluation framework is shown as Figure 1.

EWP refers to the efficiency of transforming natural consumption into welfare level. It is the goal of sustainable development to achieve higher well-being within the carrying capacity of the ecological environment. Under the premise of limited natural capital stock, if the EWP shows a gradual trend of increase, it means that the region has traded less natural capital consumption for significant improvements in well-being; at this time, the ability of regional sustainable development is gradually enhanced, which is the correct track and the best ideal state of regional sustainable development [43]. Daly put forward the concept of efficiency in sustainable development economics, which decomposed development performance into production efficiency and service efficiency; that is, two-stage efficiency [49]. The first stage is the production stage, which mainly deals with the relationship between economic growth and pressure on resources and the environment, so as to achieve the greatest economic value with the least resource consumption and environmental pollution. The second stage is the service stage of economic growth, which aims to provide important material capital for social development and improving residents' quality of life and happiness index. However, the calculation process of a single-stage DEA model is like a black box operation-it is impossible to clearly distinguish the two-stage conversion 
process and internal structure of the EWP. Hence, the network evaluation structure of the transformation process of ecological well-being is built as shown in Figure 2. The first stage is resource production efficiency (RPE), which incorporates water, energy, land, and other resources into the ecological input indicator system, with economic growth as the expected output and the emission of environmental pollution as the unexpected output. The second stage is economic service efficiency (ESE), which incorporates economic growth as an input indicator and the comprehensive well-being as an output indicator system. Economic growth serves as intermediate node connecting the two-stage network efficiency of the EWP, and thus, GDP is both the expected output of the first stage and the input of the second stage.

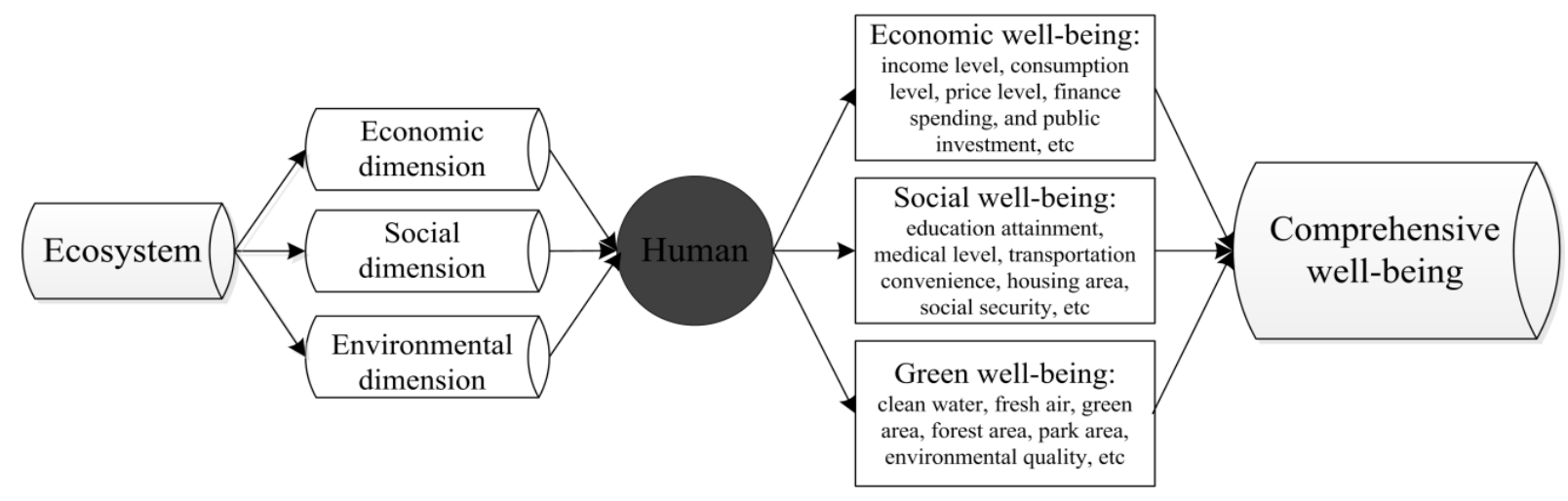

Figure 1. The evaluation framework of well-being.

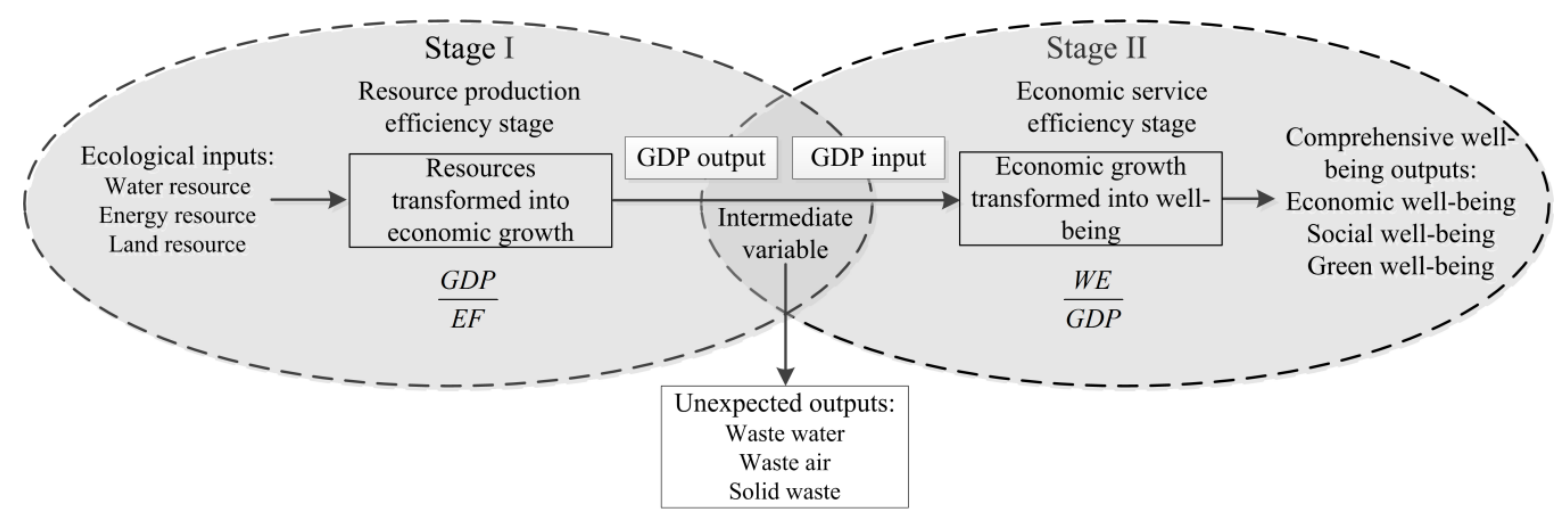

Figure 2. Network structure of ecological well-being performance transformation.

\subsection{Methods}

\subsubsection{Network DEA Model}

The traditional DEA model is based on the radial angle to measure efficiency, which requires all inputs and outputs to be reduced or expanded in the same proportion, and cannot cover slack variables, which may easily lead to high measurement results [50]. In order to solve this defect, Tone (2001) proposed the SBM model considering slack variables, which could achieve the specific slack degree of each input-output indicator during the single-stage DEA efficiency evaluation [51]. However, the single-stage efficiency measurement carried out by the traditional DEA model and SBM model considers the production process as a black box and fails to effectively evaluate the real efficiency in the operation process of the system [52]. Hence, Tone (2010) built a network DEA model based on slack variables, which could evaluate the efficiency of its sub-stages while evaluating the overall efficiency of the decision-making units [53]. To avoid the problem that multiple effective decision-making units cannot be ordered, the super efficiency network SBM model (super-NSBM), based on non-directional and non-radial considering undesirable outputs, 
is adopted from the perspective of two stages under the hypothesis of variable returns to scale. The specific formula is expressed as follows [54]:

$$
\begin{gathered}
\rho_{S E}^{*}=\min \frac{\sum_{k=1}^{K} \omega^{k}\left(1+\frac{1}{m_{k}} \sum_{i=1}^{m_{k}} s_{i}^{k} / x_{i 0}^{k}\right)}{\sum_{k=1}^{K} \omega^{k}\left[1-\frac{1}{v_{1 k}+v_{2 k}}\left(\sum_{r=1}^{v_{1 k}} \frac{s_{r}^{g k}}{y_{r 0}^{k k}}+\sum_{r=1}^{v_{2 k}} s_{r}^{b k}\right)\right]} \\
\text { s.t. } \sum_{\substack{b k 0 \\
j=1, j \neq 0}}^{n} x_{i j}^{k} \lambda_{j}^{k}+s_{i}^{k-}=\theta^{k} x_{i 0}^{k}, i=1, \cdots, m_{k}, k=1, \cdots, K \\
\text { s.t. } \sum_{j=1, j \neq 0}^{n} y_{i j}^{g k} \lambda_{j}^{k}+s^{g k}=\varphi^{k} y_{i 0}^{g k}, r=1, \cdots, s_{k}, k=1, \cdots, K \\
\text { s.t. } \sum_{j=1, j \neq 0}^{n} z_{r j}^{b k} \lambda_{j}^{k}-s^{b k}=\xi^{k} z_{r 0}^{b k}, r=1, \cdots, s_{k}, k=1, \cdots, K \\
\varepsilon \leq 1-\frac{1}{v_{1 k}+v_{2 k}}\left(\sum_{r=1}^{v_{1 k}} \frac{s_{r}^{g k}}{y_{r 0}^{g k}}+\sum_{r=1}^{v_{2 k}} \frac{s_{r}^{b k}}{y_{r 0}^{b k}}\right) \\
\overline{\lambda^{k}} \geq 0, s^{k-} \geq 0, s^{g k} \geq 0, s^{b k} \geq 0, \omega^{k} \geq 0
\end{gathered}
$$

where $m_{k}$ and $v_{k}$ represent the number of inputs and outputs of the $k$-th stage, $\varphi_{k}$ indicates the number of intermediate indicators, $(k, h)$ represents the connection from stage $\mathrm{k}$ to stage $h, x$ is the input, $y$ is the output, $z$ stands for intermediate output, $\lambda^{k}$ represents the model weight of the $k$-th stage, $\omega^{k}$ is the weight of the $k$-th stage, $s^{k-}$ is the slack variable of the input index, and $s^{g k}$ and $s^{b k}$ represent the slack variables of desirable output and undesirable output, respectively. In this study, the evaluation process is divided into two stages, then, $k=2$ and the weights of the two stages are set to be the same. When the overall efficiency, the first stage and the second-stage efficiency values are greater than or equal to 1 , the DEA of the decision-making units can be considered relatively effective. However, when one of the efficiency values is less than 1, the weak DEA is considered effective; otherwise, it is deemed invalid, indicating that it is necessary to make appropriate improvements to the input and output.

\subsubsection{Threshold Panel Regression Model}

The threshold effect refers to the phenomenon that when one parameter reaches a certain value, another parameter will change sharply and transform into another form of development. Hansen (1999) proposed that the threshold values could be determined by further minimizing the sum of squares of residual errors, which could not only accurately estimate the threshold value, but also test the significance of the threshold value, thus avoiding the statistical errors and regression errors caused by the subjective judgment of the threshold values [55]. Therefore, the non-dynamic panel threshold regression model is adopted and the double panel threshold and multiple panel threshold model is built based on the single panel threshold model. The single threshold regression formula is expressed as follows [56,57]:

$$
\ln E W P_{i t}=\ln a_{i}+\theta \ln x_{i t}+\beta_{1} \ln u r b_{i t} \times f\left(\ln q_{i t} \leq \gamma_{1}\right)+\beta_{2} \ln u r b_{i t} \times f\left(\ln q_{i t}>\gamma_{1}\right)+\varepsilon_{i t}
$$

where $i$ is cities, $t$ is time, $E W P_{i t}$ is the explanatory variable, $\theta$ is the corresponding coefficients of influencing factors, $x_{i t}$ is the control variables, $u r b_{i t}$ is the core explanatory variable affected by the thresholds, $q_{i t}$ is the threshold variables, $\gamma_{1}$ is the threshold value to be estimated, $f(\bullet)$ is the indicator function, when $\ln q_{i t} \leq \gamma_{1}, f(\bullet)=1$, and vice versa equal to zero, and $\varepsilon_{i t}$ is a random perturbation term.

A statistical test is needed to determine whether the estimated parameters and modes of the two groups of samples are significantly different divided by the threshold value. The null hypothesis of the nonexistent threshold is $H_{0}: \theta_{1}=\theta_{2}$, and the structure of LM statistics shows as:

$$
L=n \frac{S_{0}-S_{n}(\hat{\gamma})}{S_{n}(\hat{\gamma})}
$$


$S_{0}$ is the sum of the squares of the residuals under the null hypothesis. The bootstrap method is used to obtain the probability $p$ value to determine whether the significance level is significant or not. In order to further determine the confidence interval of the threshold, the null hypothesis $H_{0}: \hat{\gamma}=\gamma$ is tested. When $L R_{n}(\gamma) \leq c(a)=-2 \ln (1-a)$. When the null hypothesis is denied, it can be judged that there is at least one threshold, and further tests can determine whether the second or the third threshold exists.

\subsection{Index System}

\subsubsection{Ecological Input Indicators}

In terms of ecological input indicators, the status of ecological consumption is mainly reflected in land resources, water resources, power consumption, energy resources, etc. $[20,41,58]$. Based on the actual situation of regional development and the availability of data, the input of land resources, water resources, energy resources, and human resources is represented by the per capita built-up area, per capita water consumption, per capita energy consumption, and overall social employment rate.

\subsubsection{Unexpected Output Indicators}

Existing studies usually use industrial wastewater discharge, waste gas discharge, solid waste generation, and municipal sewage discharge to characterize the high entropy waste discharged into the ecosystem by economic activities [59,60]. Hence, this study will select per capita industrial wastewater emissions, per capita domestic sewage emissions, per capita sulfur dioxide emissions, per capita nitrogen oxide emissions, per capita smoke and dust emissions, per capita industrial solid waste production, and per capita municipal solid waste production to characterize environmental pollution.

\subsubsection{Expected Output Indicators}

The Human Development Index (HDI) is widely used to assess the level of regional well-being. However, the city is a complex and vast system. With the continuous improvement of economic development and living standards, the connotation of urban well-being is becoming more and more diversified. From the single economic dimension or social development dimension, it is difficult to comprehensively evaluate the realization of urban functions and the level of residents' well-being. Therefore, scholars are tending to build a composite index system to comprehensively evaluate the level of well-being [61-64], including income, employment, housing, health, and other indicators. In addition, in the context of rapid urbanization development and high-density construction, urban residents not only enjoy the "well-being" brought by industrialization and modernization, but also face the "urban diseases" brought by the degradation of the ecological environment and the increasingly prominent "new urban diseases" brought by social economy development. People's needs have changed from the initial stage of pursuing abundance and convenience to the advanced stage of improving the ecological environment and the quality of the human settlement environment. Returning to green ecology and nature has become an urgent social demand. Therefore, this study characterizes the realization of urban social and economic development functions from three dimensions of economy, society and environment, and the expected output evaluation system is constructed in Table 1. 
Table 1. Evaluation index systems of expected output.

\begin{tabular}{cc}
\hline Dimension & Indicator \\
\hline Economic well-being & $\begin{array}{c}\text { Per capita disposable income, Average salary } \\
\text { of employees, Per capita savings, Per capita } \\
\text { consumption level of residents, Engel }\end{array}$ \\
coefficient of urban residents *, Engel \\
coefficient of rural residents ${ }^{*}$ Consumer Price \\
Index $*$ Housing price index *
\end{tabular}

Number of doctors per 10,000 people, Average years of education, Basic medical participation rate, Urban registered unemployment rate *,

Social well-being

Per capita road area, Number of buses per

10,000 people, Housing area per resident, Internet penetration rate, Number of public toilets per 10,000 people, Number of libraries owned by thousand people

Green coverage rate of built-up area, Per capita public green areas, Forest coverage rate, Number of parks per 10,000 people, Rate of good air quality, Proportion of investment in Green well-being environmental protection and management, Discharge standard-meeting rate of industrial wastewaters, Comprehensive utilization rate of industrial solid wastes, Innocuous treatment rate of domestic waste, Urban water saving and reuse rate, $\mathrm{PM}_{2.5}$ concentration *

Note: Due to the indicator of "life expectancy" was not available at city scale, the number of doctors, hospitals and hospital beds were used instead. The employment rate of society was calculated by the ratio of employed persons to the resident population. The average education years (AEY) was described by referring to the calculation method in the Human Development Report of the United Nations Development Program (UNDP) [64]: $A E Y=\left(6 \times P_{1}+9 \times P_{2}+12 \times P_{3}+16 \times P_{4}\right) /\left(P_{1}+P_{2}+P_{3}+P_{4}\right)$, where in, $P_{1}, P_{2}, P_{3}$ and $P_{4}$ indicate the number of on-campus students of primary schools, junior high schools, senior high schools, and universities. The * indicates negative indicator.

\subsection{Data Source and Processing}

The relevant data of the evaluation index system were collected from the Statistical Yearbooks, Statistical Bulletin of National Economic and Social Development, Statistical Bulletin of Urban Health, and statistical websites of provinces and cities compiled by the government during 2001-2017. There are a total of 41 cities in the Yangtze River Delta area, including Shanghai city, Jiangsu Province, Zhejiang Province, and Anhui Province. Due to the adjustment of the administrative division of Anhui province, Chaohu city was divided into three parts in 2011 and merged into Hefei, Ma'anshan, and Wuhu city. In order to ensure administrative consistency throughout the study period, this study used the 2016 administrative divisions as the base map and merged the statistics of Chaohu city before 2011 into the three cities. Figure 3 presents the spatial distribution of 41 cities of the study area. In order to eliminate the effect of urban scale, all indicators were represented by per capita, average land value or proportion, and per capita values were converted according to the resident population. Economic data, such as GDP, consumption, and income, were converted based on the year 2001. 


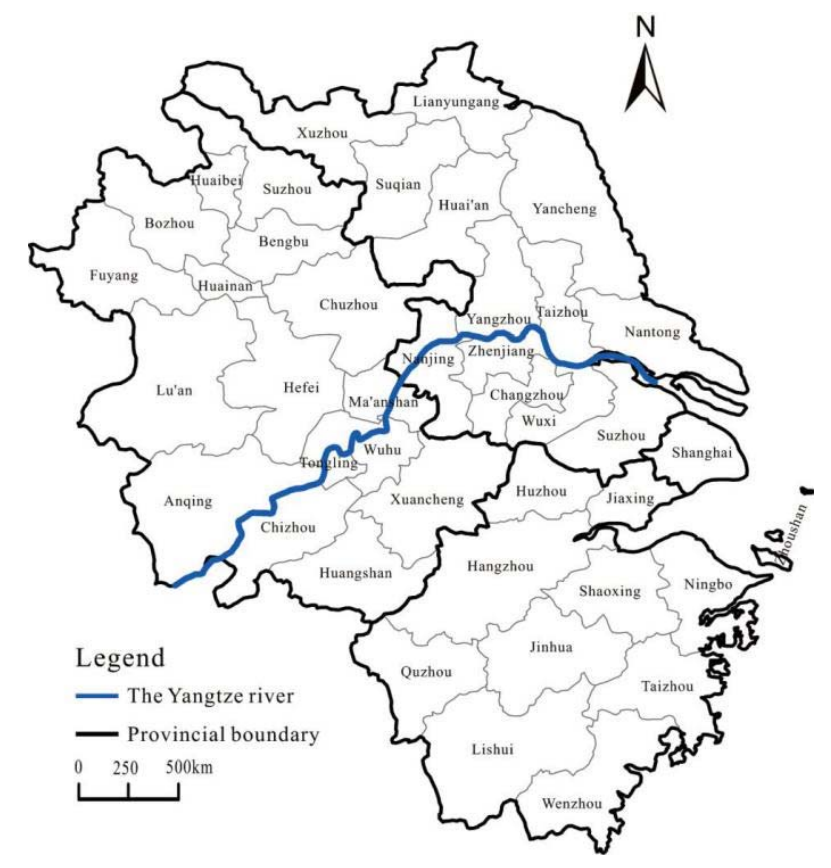

Figure 3. The study area of the Yangtze River Delta.

\section{Results}

\subsection{Spatial Analysis: Horizontal Comparison of the EWP}

By means of the MaxDEA Ultra 6.16 software, the network DEA model considering undesired outputs was used to measure the EWP of 41 cities in the Yangtze River Delta from 2001 to 2017. The EWP value was divided into five levels to visualize: higher performance $(E W P>0.8)$, high performance $(0.6<E W P \leq 0.8)$, medium performance $(0.4<E W P \leq 0.6)$, low performance $(0.2<E W P \leq 0.4)$ and lower performance $(E W P \leq 0.2)$. The visualization expression is based on the average of the four stages of 2001-2005, 2006-2010, 2011-2015, and 2016-2017 shown in Figure 4.
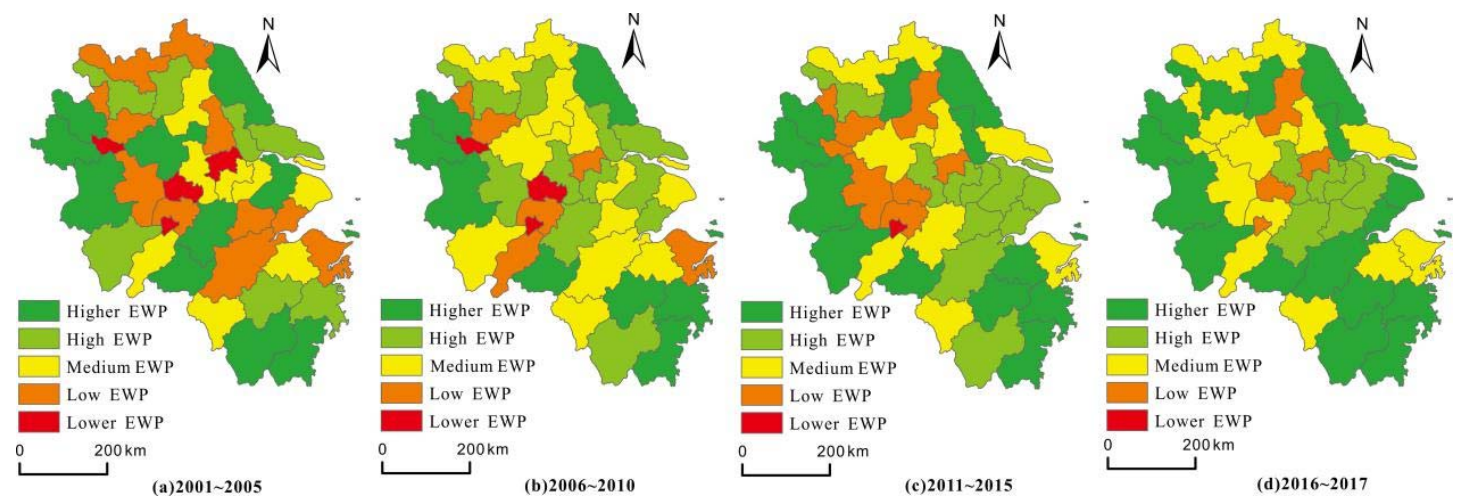

Figure 4. Spatio-temporal evolution patterns of urban EWP in the Yangtze River Delta.

On the whole, the level of the EWP is low, and there are big differences in the EWPs of different cities. As time goes on, the average value of the EWP steadily increases, the spatial scope of the lower and low performance regions tends to shrink, and the spatial scope of high and higher performance regions tends to expand. Most cities achieve a gradual transformation from the low- and medium-performance level to the higher performance level. From 2001 to 2005, five cities-namely, Huangshan, Fuyang, Zhoushan, Lishui, and Wenzhou-had the highest EWP levels, but only Huangshan and Fuyang city achieved the effective DEA, while the DEA of other cities is ineffective, with an inefficiency rate of $95.12 \%$. After 2016, Lu'an, Huangshan, Bozhou, Fuyang, Taizhou, Wenzhou, Jinhua, 
Anqing, and other cities all achieved DEA effectiveness, and the effective rate increased by $14.63 \%$. Cities with low EWP levels mainly include Ma'anshan, Tongling, Huainan, Zhenjiang, Wuhu, Huai'an, Bengbu, and other cities. Among them, the EWP of Ma'anshan, Tongling, Huainan, Zhenjiang, Wuhu, and other cities rank at the bottom in different stages. These cities face with many disadvantages such as a backward industrial structure, low return on investment, and high energy consumption in economic growth; this mode of heavy pollution and high energy consumption restricts the significant improvement of urban EWP. However, economically developed cities such as Shanghai, Nanjing, Wuxi, Hangzhou, and Ningbo also have the lower EWP than the average level of the whole region, ranking below the medium level; this is due to the fact that the excessive investment of natural capital offsets the effect of economic development on the improvement of EWP, and economically developed cities are in a state of high economic development and high resource consumption.

From the perspective of intraregional difference, the EWP of Anhui province has a large gap, which is mixed by both the highest EWP and the worst EWP city. The level of urban EWP in Zhejiang province is relatively balanced, most of which belong to the middle and upper-middle level, and some cities are of high level. The urban EWP of Jiangsu Province is in the middle and lower level, and there are fewer cities with higher level. Meanwhile, it can be found that cities with high EWP during the study period were mainly distributed in the peripheral areas of the whole region. The most typical city is Huangshan, which has always been in a state of high well-being and low consumption; this is closely related to the dominant development of the tourism industry that is low energy consumption and eco-friendly. In terms of the spatial structure of EWP, there is an obvious spatial mismatch between urban economic development and EWP, and the EWP of economically developed cities is significantly lower than that of less economically developed areas. The main reason is that the excessive agglomeration of the industrial economy makes the cities in the core area of the Yangtze River Delta in the mode of high welfare, high consumption, and low performance, which intensifies the negative effects of economic growth and counteracts the positive well-being caused by industrial economic growth. In particular, resource-based cities such as Huainan, Ma'anshan and Tongling have fallen into the resource curse circle due to their rich mineral or energy resources, fewer resource consumption restrictions, and serious environmental pollution, and have become the most typical low EWP cities.

It can be seen that the rapid development of urbanization, on the one hand, increases residents' income and consumption level, and then improves the allocation of infrastructure and public service resources such as education, health care, and public transportation, which plays a role in optimizing and promoting urban EWP. However, on the other hand, the rising housing prices, environmental pollution, widening urban-rural gap, living space squeezing, land shortages, and other problems behind the rapid development of urbanization decrease the EWP of regional cities, and they enter the bottleneck period of "high economic growth and low well-being growth". It can be anticipated that with the transformation of economic growth modes, the optimization of industrial structures, and the improvement of people's livelihood security system, the growth of natural capital consumption will be restricted to a certain extent, the growth rate of economic and social welfare will be faster than the rate of resource consumption, and the performance of ecological welfare will be gradually optimized.

\subsection{Stage Analysis: Comparison of Production Efficiency and Service Efficiency}

In order to clearly understand the stage change process of urban EWP, it is necessary to compare production efficiency and service efficiency by a two-dimensional scatter plot. In view of the average level of production efficiency and service efficiency, regional cities are divided into four development modes with 0.8 as the dividing line, namely, high production efficiency-high service efficiency ("double high", $\mathrm{HH}$ ), high production efficiency-low service efficiency ("high-low type", HL), low production efficiency-low 
service efficiency ("double low type", LL), and low production efficiency-high service efficiency ("low-high type", LH). The HH mode represents the ideal state of sustainable development with lower resource consumption and environmental pollution to create a higher level of well-being and achieve the coordinated development of the three major systems of economy, society, and ecology being realized. The LH mode characterizes the output of high well-being and the low-efficiency utilization of natural resources. The HL mode implies that the service conversion effect of production needs to be improved. The LL mode represents the most unsustainable state, with economic development and well-being improvement consuming excessive resources and the environment. ArcGis 10.5 software was used to visualize these modes, as shown in Figure 5.
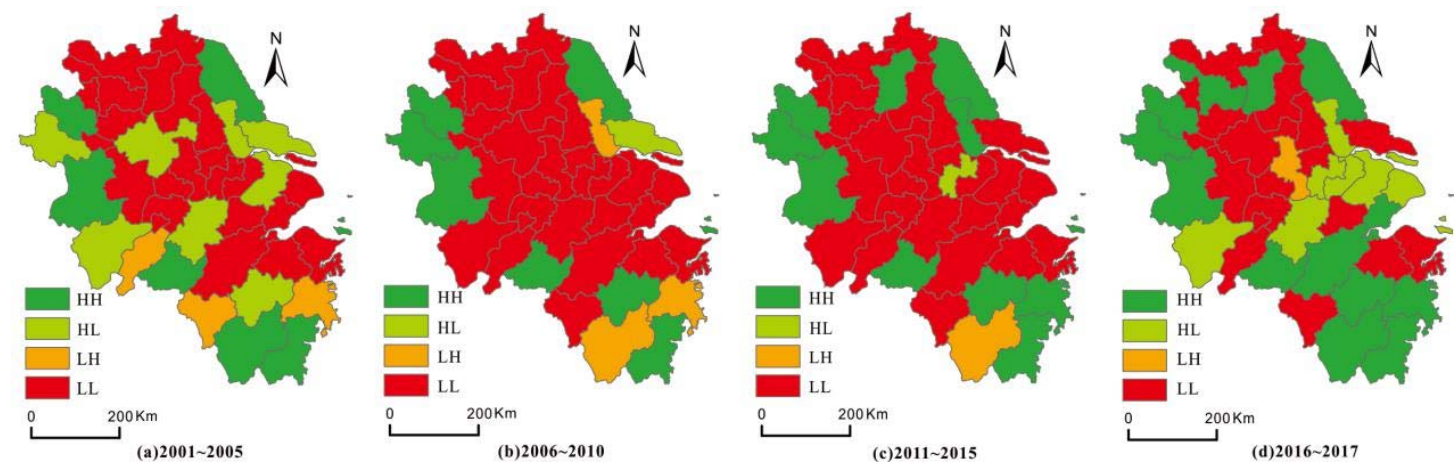

Figure 5. Production efficiency and service efficiency development modes in the Yangtze River Delta.

From 2001 to 2005, the number of LL modes accounts for a large proportion, as high as $56.098 \%$, especially distributed in economically developed cities such as Shanghai, Nanjing, Hangzhou, Hefei, Ningbo, Wuxi, Jiaxing, Zhenjiang, etc. This is due to their developed industrial economy, intensive manufacturing and heavy chemical industries, large resource consumption, and serious environmental pollution, which results in low EWP conversion efficiency and forms the typical extensive development mode of "high economic growth, high resource consumption, and low well-being performance". In particular, the representative resource-based cities, such as Tongling and Ma'anshan, have extremely low production efficiency. Huangshan, Zhoushan, Yancheng, Wenzhou, Lu'an, Lishui, Bozhou, Xuancheng, and other cities belong to the typical HH mode. These cities have strong sustainable development capabilities due to lower levels of economic development consuming less ecological capital, but providing high levels of well-being output. However, the number of LH and HL types is relatively small, accounting for only $24.390 \%$. Among them, Taizhou, Chizhou, and Quzhou have higher service efficiency than production efficiency, belonging to the mode of lagged production efficiency. While the service efficiency of Jinhua, Fuyang, Taizhou, Chuzhou, Anqing, Nantong, Suzhou, and other cities is far lower than production efficiency, improving service efficiency is their key optimization direction.

From 2006 to 2010, the number of cities presenting LL modes show an increasing trend, accounting for $68.293 \%$. Economically developed cities are still dominant, with production efficiency and service efficiency within the range of 0.4-0.6. However, the number of cities with HH and HL modes has decreased. This stage is not only a golden period of China's social and economic development, but also a period of prominent contradictions, increased pressure on resources and the environment, and defects in systems and mechanisms that constrain the speed and quality of economic development. The extensive growth mode characterized by high investment, high consumption, and low income is becoming increasingly difficult to sustain, and the development gap between regions and between cities is widening. Due to the huge impact of industrialization, urbanization, marketization, and globalization, the increase in economic operation costs makes it difficult to effectively improve the EWP. In the face of major changes in the process of industrialization and urbanization, economically developed cities are the first to embark on a new path of 
industrialization with technological innovation as the core, adhering to the principle of saving resources and reducing production costs, and thus improving production efficiency faster than service efficiency.

From 2011 to 2015, the development mode of EWP in most cities has gradually improved, and the ability of sustainable development has improved. Specifically, the proportion of LL cities has decreased to $60.976 \%$, and the number of $\mathrm{HH}$ cities has increased to $26.829 \%$. In the face of structural contradictions and the pressures of transformation and development that have accumulated over the years, the impact of the "three-phase superposition" (slower economic growth, difficult structural adjustments, and early-stage stimulus policy digestion period) has continued to deepen. The government has taken the initiative to adjust the direction of economic development, with industrial structure adjustment and reform aiming to promote the well-being of the people, increase investment in social programs, increase urban employment and social health care, improve the social security system covering urban and rural residents, and promote equal access to basic public services. Therefore, urban residents' quality of life has been effectively improved.

Since 2016, the number of cities with the LL mode has been reduced significantly. The number of $\mathrm{HH}$ and HL cities has increased significantly. Compared with the base year, the EWP of each city has been effectively improved. This is due to the fact that the economic development of most cities has entered a critical period of transformation and upgrading, and the EWP has been significantly improved. For example, Yancheng, Suqian, Hangzhou, Jinhua, Wenzhou, Jiaxing, Taizhou, Lishui, Huangshan, Lu'an, Bozhou, Suzhou, Fuyang, and other cities have achieved sustainable development with the best EWP. Both production efficiency and service efficiency have reached higher levels, achieving the maximum level of welfare created with minimal ecological consumption.

\subsection{Influencing Factors of Urban EWP}

\subsubsection{Selection of Influencing Factors}

The evolution of urban EWP is affected by many factors, such as economic development, urbanization level, urban compactness, technological innovation, industrial structure, foreign economic relations, and energy consumption [44-48]. Existing studies have selected multi-dimensional indicators such as climate environment, human capital, social capital, industrial structure, energy structure, urbanization level, foreign investment level, economic contribution rate, technological progress, green technology innovation efficiency, and population effect for analysis. Based on the actual regional development, indicators including urbanization, population density, economic growth, consumption level, industrialization level, advanced industrial structure, foreign direct investment, environmental regulation, energy efficiency, technological innovation, government policy, and environmental quality are selected to detect their impact on urban EWP (Table 2).

Table 2. The selection of influencing factors of urban EWP.

\begin{tabular}{|c|c|c|c|}
\hline Independent Variable & Symbol & Calculation Method & Unit \\
\hline Urbanization & $X 1$ & Urban population/resident population $\times 100 \%$ & $\%$ \\
\hline Population density & $X 2$ & Permanent population/city area & person $/ \mathrm{km}^{2}$ \\
\hline Economic Growth & X3 & GDP per capita & Yuan \\
\hline Consumption level & $X 4$ & Retail sales of consumer goods/resident population & Yuan \\
\hline Industrialization level & X5 & $\begin{array}{c}\text { Industrial output value/Gross regional } \\
\text { product } \times 100 \%\end{array}$ & $\%$ \\
\hline Industrialization & $X 6$ & $\begin{array}{l}\text { Added value of tertiary industry/added value of } \\
\text { secondary industry } \times 100 \%\end{array}$ & $\%$ \\
\hline Foreign direct investment & $X 7$ & $\begin{array}{c}\text { Foreign direct investment/total social fixed } \\
\text { investment } \times 100 \%\end{array}$ & $\%$ \\
\hline Environmental regulation & $X 8$ & $\begin{array}{l}\text { Total Environmental Governance Investment/ } \\
\qquad \text { GDP } \times 100 \%\end{array}$ & $\%$ \\
\hline Energy efficiency & $X 9$ & GDP/Energy Consumption & $\begin{array}{l}10,000 \text { yuan/ton of } \\
\text { standard coal }\end{array}$ \\
\hline Technological innovation & X10 & Number of patents granted & million pieces \\
\hline Government policy & $X 11$ & Fiscal expenditure/GDP $\times 100 \%$ & $\%$ \\
\hline Environmental Quality & X12 & Air quality index & $\%$ \\
\hline
\end{tabular}




\subsubsection{Threshold Effect Diagnostics}

In order to avoid spurious regression, the ADF-Fisher, HT, and IPS test methods are first used to test the stability of variables. The test results showed that all variables are stable and there is no unit root, so the spurious regression problem of non-stationary series can be eliminated. Second, the diagnosis of variance inflation factor (VIF) shows that the VIF value of each indicators is less than 10, and the Hausman test rejects the random effect model. The threshold effect is further tested, taking urbanization indicators as the core variable, using the bootstrap method to test the significance of the threshold effect. The test results show that population density, industrialization, and environmental regulation have significant single threshold effects (Table 3). Therefore, population density (X2), industrialization (X5), and environmental regulations (X8) are used as threshold variables, respectively, and other factors and threshold variables are included in the control variable sets. The estimation results of the panel threshold model are summarized in Table 4 using Stata 15.0 software.

Table 3. Threshold estimation and test of threshold variables.

\begin{tabular}{ccccccccc}
\hline $\begin{array}{c}\text { Core } \\
\text { Variables }\end{array}$ & $\begin{array}{c}\text { Threshold } \\
\text { Variable }\end{array}$ & $\begin{array}{c}\text { Threshold } \\
\text { Number }\end{array}$ & $\begin{array}{c}\text { Threshold } \\
\text { Value }\end{array}$ & F-Value & $\boldsymbol{p}$-Value & $\mathbf{1 \%}$ & $\mathbf{5 \%}$ & $\mathbf{1 0 \%}$ \\
\hline \multirow{3}{*}{ X1 } & $X 2$ & single & 225.734 & 31.130 & 0.023 & 24.541 & 28.213 & 34.921 \\
& $X 5$ & single & $34.000 \%$ & 19.670 & 0.051 & 15.042 & 17.879 & 21.865 \\
& $X 8$ & single & $0.396 \%$ & 18.450 & 0.083 & 16.086 & 19.371 & 27.276 \\
\hline
\end{tabular}

Notes: $X 1, X 2, X 5$ and $X 8$ represent urbanization, population density, industrialization level, and environmental regulation.

Table 4. Regression results of threshold effect of each variable.

\begin{tabular}{|c|c|c|c|c|c|c|c|}
\hline Variables & $X 2$ & $X 5$ & $X 8$ & Variables & $X 2$ & $X 5$ & $X 8$ \\
\hline$X 2$ & $\begin{array}{l}0.401 \\
(1.27)\end{array}$ & $\begin{array}{l}0.337 \\
(1.07)\end{array}$ & $\begin{array}{l}0.484 \\
(1.54)\end{array}$ & $X 9$ & $\begin{array}{c}0.075^{* * *} \\
(6.61)\end{array}$ & $\begin{array}{c}0.076^{* * *} \\
(6.75)\end{array}$ & $\begin{array}{c}0.076^{* * *} \\
(6.81)\end{array}$ \\
\hline X3 & $\begin{array}{c}-0.290^{* * *} \\
(-2.79)\end{array}$ & $\begin{array}{c}-0.288^{* * *} \\
(-2.77)\end{array}$ & $\begin{array}{c}-0.304^{* * *} \\
(-2.95)\end{array}$ & X10 & $\begin{array}{c}0.306^{* * *} \\
(3.23)\end{array}$ & $\begin{array}{c}0.289 * * * \\
(3.07)\end{array}$ & $\begin{array}{c}0.312^{* * *} \\
(3.34)\end{array}$ \\
\hline$X 4$ & $\begin{array}{c}0.447^{* * *} \\
(4.43)\end{array}$ & $\begin{array}{c}0.438^{* * *} \\
(4.36)\end{array}$ & $\begin{array}{c}0.410 * * * \\
(4.11)\end{array}$ & X11 & $\begin{array}{c}-0.751^{* * *} \\
(-3.41)\end{array}$ & $\begin{array}{c}-0.716^{* * *} \\
(-3.25)\end{array}$ & $\begin{array}{c}-0.745^{* * *} \\
(-3.42)\end{array}$ \\
\hline X5 & $\begin{array}{c}-0.512^{* *} \\
(-2.21)\end{array}$ & $\begin{array}{c}-0.435 * \\
(-1.87)\end{array}$ & $\begin{array}{c}-0.569 * * \\
(-2.48)\end{array}$ & X12 & $\begin{array}{l}0.113 \\
(1.62)\end{array}$ & $\begin{array}{l}0.111 \\
(1.60)\end{array}$ & $\begin{array}{l}0.091 \\
(1.32)\end{array}$ \\
\hline$X 6$ & $\begin{array}{c}0.104^{* *} \\
(2.06)\end{array}$ & $\begin{array}{c}0.113^{* *} \\
(2.22)\end{array}$ & $\begin{array}{c}0.112^{* *} \\
(2.22)\end{array}$ & X1_1 & $\begin{array}{l}-0.051 \\
(-0.23)\end{array}$ & $\begin{array}{c}0.434^{* * * *} \\
(2.82)\end{array}$ & $\begin{array}{l}0.187 \\
(1.33)\end{array}$ \\
\hline$X 7$ & $\begin{array}{l}0.156 \\
(0.98)\end{array}$ & $\begin{array}{l}0.025 \\
(0.15)\end{array}$ & $\begin{array}{l}0.173 \\
(1.11)\end{array}$ & $X 1 \_2$ & $\begin{array}{c}0.276^{*} \\
(1.96)\end{array}$ & $\begin{array}{c}0.286^{* *} \\
(2.03)\end{array}$ & $\begin{array}{c}0.338^{* *} \\
(2.42)\end{array}$ \\
\hline$X 8$ & $\begin{array}{l}-0.016 \\
(-1.29)\end{array}$ & $\begin{array}{l}-0.016 \\
(-1.28)\end{array}$ & $\begin{array}{c}-0.037^{* * *} \\
(-2.83)\end{array}$ & _cons & $\begin{array}{c}0.556^{* * *} \\
(3.63)\end{array}$ & $\begin{array}{c}0.514^{* * * *} \\
(3.36)\end{array}$ & $\begin{array}{c}0.612 * * * \\
(4.03)\end{array}$ \\
\hline
\end{tabular}

Note: (1) ${ }^{* * *}, * *, *$ are significant at $1 \%, 5 \%$, and $10 \%$, respectively; (2) the t-statistic of coefficient estimation is in parentheses. $X 2, X 3, X 4, X 5$, $X 6, X 7$, and $X 8$ represent population density, economic growth, consumption level, industrialization level, industrialization, foreign direct investment, and environmental regulation, respectively.

\subsubsection{Threshold Effect Analysis of Estimated Results}

Urbanization shows a U-shaped relationship with the EWP when population density is taken as a threshold variable. When population density is lower than 225.734 people $/ \mathrm{km}^{2}$, urbanization has a negative but not significant impact on the EWP. When population density exceeds the threshold, the elasticity coefficient of urbanization is positive and through the $10 \%$ statistical level test, indicating the enhancing impact of urbanization on the EWP, thus forming a U-shaped influence change. This is due to the phased effect of population agglomeration on urbanization. The moderate regional population agglomeration increases population density and city size-which is beneficial to the centralized allocation of land, water, and energy resources-and the improvement of resource utilization efficiency. However, the increase in excessive population density will also bring about traffic congestion, rising housing prices, reducing per capita living space, and other urban diseases. Similarly, 
the impact of population density on urban EWP is positive but insignificant, implying the impact of the threshold effect.

Taking the level of industrialization as the threshold effect variable, urbanization always has a positive impact on the EWP. When the industrialization level is lower than $34.0 \%$, the elasticity coefficient of urbanization on the EWP is 0.434 , indicating a significant positive promoting effect. When the industrialization level exceeds the threshold value of $34.0 \%$, the elasticity coefficient of urbanization on the EWP decreases to 0.286 , indicating a weakening promoting effect. When the level of industrialization is low, the industrial structure is dominated by a simple resource-based or processing-based industry with less pressure on ecological environment. With the improvement of the industrialization level, it promotes the spatial agglomeration of urban production factors. The scale economy brought by the expansion of production scale further promotes urbanization into the medium-term development stage, and the industrial development system is gradually improved, which lays a sufficient material foundation for urban social and economic development. Due to the ecological environment pressures of the extensive growth modes, the improvement of urban well-being suffers offset trend, but with the improvement of cleaner production technology and equipment, this offset effect has been weakened.

When environmental regulation is taken as the threshold effect variable, the positive impact of urbanization on the EWP is gradually strengthened, indicating that urbanization has different impacts on the EWP in different development stages of environmental governance. During a period of weak awareness of environmental protection and incentive financial performance appraisal mechanisms, although the increasingly serious environmental pollution forces the government to introduce strict environmental regulatory policies and measures to improve ecological environment quality through "compensation effect" and the "reverse conduction effect", urban economic growth is the primary goal. The increase of short-term investments in environmental governance will increase the economic operation costs; therefore, urbanization has an insignificantly positive impact on the EWP due to the existence of an "offset effect" and a "restraint effect". With high-quality and green development becoming the main theme of urban development, there is an increasing trend of the scale and proportion of environmental governance investment, and with the elimination of backward production capacity and the research and development of clean production technology, the pressure on the ecological environment caused by fast urbanization is gradually alleviated, and urban EWP is significantly improved.

Under the threshold effect of population density, industrialization, and environmental governance, the elasticity coefficients of economic growth to urban EWP are $-0.290,-0.288$, and -0.304 , respectively, which all significantly pass the statistical level test of $1 \%$. This is due to the excessive pursuit of high GDP growth resulting in high resource consumption and environmental pollution, a series of social and environmental problems that hinder the effective improvement of urban well-being. The influence coefficients of consumption levels on urban EWP are $0.447,0.438$, and 0.410 , respectively, and significantly pass the $1 \%$ statistical level test, indicating that the increase in consumption levels effectively promotes the improvement of urban EWP. The improvement of consumption levels indicates that the higher the satisfaction and utility of residents to the value they own, the more they can transform that value into material and non-material subjective enjoyment and experience, thereby enhancing their personal sense of acquisition and satisfaction. The effect of industrial structure on urban EWP is significant and positive, and the elastic coefficients are 0.104, 0.113 , and 0.112 , respectively, passing the statistical significance test of $5 \%$. This is due to the fact that the industrial structure in the Yangtze River Delta is gradually becoming more rationalized and advanced. Foreign direct investment has a positive but not significant effect on urban EWP. This is due to the fact that on one hand, the high level of regional openness and frequent foreign economic contacts attract large amounts of foreign capital, which greatly promotes the local labor employment and economic development, and also improves urban production efficiency and management efficiency through the spillover effect of advanced management ideas and technology. On the other hand, foreign direct 
investment also brings local resource consumption and environmental pollution, which become obstacles to the improvement of urban development quality. The impact of energy efficiency on urban EWP is significantly positive, due to the fact that the improvement of energy efficiency can significantly reduce the high consumption of resources and the pressure on the ecological environment. Technical innovation exhibits significant positive impact on urban EWP; this is due to the fact that the improvement of production technology can effectively reduce energy consumption per unit output value, and technical progress also provides great convenience and superiority for residents' lives. The impact of government policy on urban EWP is significantly negative, and the elastic coefficients are $-0.751,-0.716$, and -0.745 , respectively, which indicates the macro-control of the regional government has not played its due role in the process of improving urban EWP. The influence coefficients of environmental quality on urban EWP are $0.113,0.111$, and 0.091 , respectively, but the test of the statistical significance level is not significant as the current effectiveness of comprehensive administration of the environment is not significant.

In general, the spatio-temporal evolution of urban EWP in the Yangtze River Delta is the result of the interactions and dynamic game among elements of the economy, resources, environment, technology, and well-being. Driven and restrained, promoted and offset by various factors such as economic growth mode, urbanization development mode, city scale, consumption, industrial structure, technological innovation, environmental governance effectiveness, regional policies, and other factors, it directly affects the use of urban ecosystems and the realization of human well-being and presents a certain threshold effect in the time series. The threshold effect is mainly formed by the superposition of the driving effect, inhibiting effect, offsetting effect, and regulating effect of different factors.

\section{Discussion}

Ecological well-being has become a new research perspective and analytical tool to test whether sustainable development can effectively reduce ecological consumption and increase well-being, or whether sustainable development can promote human wellbeing within the limited capacity of ecological capital. The ecological environment of the Yangtze River Delta has been seriously overloaded for a long time and is facing serious ecological environmental risks. With $2.14 \%$ of the country's land, it has $11.7 \%$ of its population and $20 \%$ of its GDP, which is not only the one of the highest in China's economic contribution, but also is one of the highest in the intensity of resource and energy consumption and pollutant emission intensity per unit of land area. This situation has seriously affected the construction of an urban ecological civilization and the sustainability of the city. The measure is well suited for the Yangtze River Delta, an economically developed region facing serious problems, such as resource shortages, environmental pollution, and severe ecological destruction, and has a strong policy guiding significance to reduce the consumption of natural resources and improve the quality of life and happiness of urban residents.

Compared with the existing studies, this paper mainly explores the spatial-temporal evolution law and formation mechanism of urban ecological welfare performance from the perspective of spatial analysis, which expands the research depth of urban ecological welfare performance and enriches the existing research content of ecological welfare performance. Second, this study uses the composite indicators of economy, society, and the environment to represent urban well-being, avoiding the inadequacy of a single index system, and then characterizes the state of ecological well-being in terms of ecological well-being performance and its staged efficiency changes. Third, it is helpful to deepen the understanding of the evolution mechanisms of urban ecological well-being performance to examine the evolution characteristics of urbanization on ecological well-being performance based on the threshold relationship. Although the EWP of most cities has increased since 2001, the EWP in the Yangtze River Delta does not translate to the sustainable development mode of "high production efficiency and high service efficiency". The coupling mode of the production efficiency and service efficiency of ecological well-being performance can 
help identify its shortcomings pertaining to "production efficiency" or "service efficiency", providing targeted measures to improve the ecological well-being performance.

Admittedly, there are still some deficiencies in this study. First, academics have not reached a consensus on the evaluation system of ecological well-being performance, and due to the influence of the availability of research data, the selection of evaluation indicators of urban ecological well-being performance in this study may be biased, affecting the accuracy of evaluation results. Secondly, urban ecological well-being performance has obvious spatial differentiation, and the analysis of the influencing factors of urban ecological well-being performance does not take into account the heterogeneity of different development level and scale city. In the future, the influence of different factors on different development levels and scale of cities can be diagnosed with the help of a panel geographically weighted regression model. Third, the driving forces of both production efficiency and service efficiency can be further explored to diagnose the obstacle factors of ecological welfare performance by using the panel regression model.

\section{Conclusions and Policy Suggestions}

The study on urban ecological well-being performance is important to provide guidance for the construction of ecological civilizations and the high-quality integrated development of the Yangtze River Delta. Based on the super network DEA model, the ecological well-being performance evaluation index system was established to evaluate the overall and stage efficiency of 41 cities in the Yangtze River Delta from 2001 to 2017. Then, the spatio-temporal evolution process, the development mode, and threshold influencing effect of the EWP was analyzed. The main conclusions are as follows:

(1) From 2001 to 2017, the average value of urban EWP steadily increased and most cities changed from the low and medium levels of EWP to higher levels. However, there was a big gap between high and low EWP within provinces, especially the EWP of Anhui Province, which is mixed with both low and high levels. Additionally, there was an obvious spatial mismatch between urban economic development levels and EWP. Cities with higher EWP are mainly distributed in the peripheral regions, while the EWP of economically developed cities is relatively lower.

(2) Overall, the development mode of urban EWP in the Yangtze River Delta has been continuously optimized, and the sustainable development ability of cities has gradually improved. The number of cities with HH modes has gradually increased since 2001, mainly distributed in the economically underdeveloped and low industrialization level areas. The number of cities with LL modes has been greatly decreasing. The number of LH modes cities decreased to one, while the number of cities with HL modes experienced a trend of decreasing first and then increasing.

(3) Under the effect of the population density threshold, the impact of urbanization on the EWP exhibits a U-shaped curve relationship that first drops and then rises. Under the effect of the industrialization threshold, the impact of urbanization on the EWP exhibits shows a positive driving effect, first strong and then weak. Under the influence of the environmental governance investment threshold, the driving effect of urbanization on the EWP is manifested as a positive impact that first weakens and then increases. Population density, foreign investment, and environmental quality have a positive but insignificant impact on the EWP. Economic growth, industrialization, and government policy have significantly negative inhibitory effect on the EWP, while consumption level, advanced industrial structure, energy efficiency, and technological innovation have significantly positive driving effects on the EWP. However, investments in environmental governance show an insignificantly negative restraint effect on the EWP.

To improve urban ecological well-being performance, relevant policy recommendations are proposed as follows. First, build a networked governance mode of multiple co-governances of the ecological environment. The improvement of urban ecological wellbeing performance needs the building of a multi-agent collaborative governance system; the networked governance of both the ecological environment and social services is effec- 
tive combination. Hence, it is necessary to build a pluralistic and co-governance networked governance policy system for the ecological environment incorporating stakeholders such as the government, enterprises, and the public into the environmental governance process. More specifically, it is necessary to realize the transformation of the traditional environmental governance mode led by the government into a new governance mode with the joint action of the government, enterprises, and individuals, eventually by actively forming a multi-government networked governance mode of "government-led, enterprise-driven, social participation, and collaborative progress".

Second, it is necessary to strengthen investments in scientific and technological innovation and optimize energy and industrial structures. Local governments should emphasize fiscal expenditures on science and technology research and development in the field of environmental protection, and strengthen the effective coordination of production, education, and research to transform innovation achievements into material support and management services, and pay more attention to the development of waste treatment technology, reuse technology, and environmental pollution control technology. In addition, it is necessary to actively build a multi-agent collaborative governance system and to promote the development of the industrial structure in the direction of rationalization and advancement to improve energy efficiency and achieve high-quality economic growth.

Third, it is necessary to promote the transformation of government services to welfarism with the goal of improving well-being. The government should strengthen social security and improve residents' livelihoods by increasing the supply of public services such as medical care, education, transportation, and housing, which can increase the direct happiness and ecological services that residents get from nature and improve the overall happiness index of residents. Moreover, governments should give full play to the effect of regional spatial connection, optimize the functional positing of each elements in the improvement of well-being level, and guide the balanced distribution of production factors such as capital, human resources, and other factors of production. More importantly, the traditional growth mode of purely pursuing GDP evaluation criteria should be abandoned, and there should be a shift from a materialistic consumption mode to a functionalist consumption mode, and a shift to smart development oriented towards the quality of life. Based on residents' life satisfaction and happiness index, the ecological environmental protection and governance performance indicators should be incorporated into the performance evaluation system of local governments, and well-being promotion should be fully penetrated and deeply integrated into the process of economic and social development.

Author Contributions: Conceptualization, M.H. and Z.L.; methodology, Z.L.; formal analysis, M.H. and Z.L.; writing-original draft preparation, M.H.; writing-review and editing, S.S.; supervision, Z.L. and S.S. All authors have read and agreed to the published version of the manuscript.

Funding: This research was funded by Humanities and Social Sciences Youth Foundation, Ministry of Education of the People's Republic of China, grant number 20YJCZH080 and Social Science Foundation of Jiangsu Province, grant number 20SHD009, 18EYD001.

Institutional Review Board Statement: Not applicable.

Informed Consent Statement: Not applicable.

Data Availability Statement: Not applicable.

Acknowledgments: We thank the academic editors and anonymous reviewers for their kind suggestions and valuable comments.

Conflicts of Interest: The authors declare no conflict of interest.

\section{References}

1. Xu, F.N.; Su, J.Y. Shaping "A community of shared future for mankind": New elements of General Assembly Resolution $72 / 250$ on further practical measures for the PAROS. Space Policy 2018, 44-45, 57-62. [CrossRef]

2. Alcalmo, J.; Ash, N.J.; Butler, C.D.; Callicott, B.; Capistrano, D.; Carpenter, S.R.; Castilla, J.C.; Chambers, R.; Chopra, K.; Cropper, A.; et al. Ecosystems and Human Well-Being: A Framework for Assessment; Island Press: Washington, DC, USA, 2003. 
3. Liu, J.G.; Dietz, T.; Carpenter, S.R.; Alberti, M.; Folke, C.; Moran, E.; Pell, A.N.; Deadman, P.; Kratz, T.; Lubchenco, J.; et al. Complexity of coupled human and natural systems. Science 2007, 317, 1513-1516. [CrossRef] [PubMed]

4. Liu, J.G.; Dietz, T.; Carpenter, S.R.; Taylor, W.W.; Alberti, M.; Dedman, P.; Redman, C.; Pell, A.; Folke, C.; Ouyang, Z.Y.; et al. Coupled human and natural systems: The evolution and applications of an integrated framework. Ambio 2021, 36, 639-649. [CrossRef]

5. Daly, H.E. Steady-state economics versus growth mania: A critique of the orthodox conceptions of growth economics. Policy Sci. 1974, 5, 149-167. [CrossRef]

6. Daly, H.E. Beyond Growth: The Economics of Sustainable Development; Beacon Press: Boston, MA, USA, 1996.

7. Victor, P.A. Questioning economic growth. Nature 2010, 468, 370-371. [CrossRef] [PubMed]

8. Costanza, R.; Daly, L.; Fioramonti, L.; Giovannini, E.; Kubiszewski, I.; Mortensen, L.F.; Pickett, K.E.; Ragnarsdottir, K.V.; Vogli, R.D.; Wilkinson, R.; et al. Modelling and measuring sustainable well-being in connection with the UN sustainable development goals. Ecol. Econ. 2016, 130, 350-355. [CrossRef]

9. Reid, W.V.; Mooney, H.A.; Cropper, A.; Capistrano, D.; Carpenter, S.R.; Chopra, K.; Dasgupta, P.; Dietz, T.; Duraiappah, A.K.; Hassan, R.; et al. Ecosystems and Human Well-Being: General Synthesis; Island Press: Washington, DC, USA, 2005.

10. Michalos, A.C.; Smale, B.; Labonté, R.; Muharjarine, N.; Scott, K.; Moore, K.; Swystun, L.; Holden, B.; Bernardin, H.; Dunning, B.; et al. The Canadian Index of Well-Being; Technical Report 1.0; Canadian Index of Well-Being and University of Waterloo: Waterloo, ON, USA, 2011.

11. Zheng, W.; Shi, P.H.; Chen, S.; Zhang, C.H.; Ding, D.W. Ecosystem service function from the perspective of welfare economic. Ecol. Econ. 2006, 6, 78-81. (In Chinese)

12. Barbier, E.B. The green economy post Rio+20. Science 2012, 338, 887-888. [CrossRef]

13. Max-Neef, M. Economic growth and quality of life: A threshold hypothesis. Ecol. Econ. 1995, 15, 115-118. [CrossRef]

14. Niccolucci, V.; Pulselli, F.M.; Tiezzi, E. Strengthening the threshold hypothesis: Economic and biophysical limits to growth. Ecol. Econ. 2007, 60, 667-672. [CrossRef]

15. Long, L.J. Evaluation of ecological civilization construction performance and its international comparison the perspective of overall well-being. J. Nat. Resour. 2019, 34, 1259-1272. (In Chinese)

16. Dietz, T.; Jorgenson, A.K. Towards a new view of sustainable development: Human well-being and environmental stress. Environ. Res. Lett. 2014, 9, 1-3. [CrossRef]

17. Feng, Y.J.; Zhong, S.Y.; Li, Q.Y.; Zhao, X.M.; Dong, X. Ecological well-being performance growth in China (1994-2014): From perspectives of industrial structure green adjustment and green total factor productivity. J. Clean. Prod. 2019, $236,117556$. [CrossRef]

18. Common, M. Measuring national economic performance without using prices. Ecol. Econ. 2007, 64, 92-102. [CrossRef]

19. Dietz, T.; Rosa, E.A.; York, R. Environmentally efficient well-being: Rethinking sustainability as the relationship between human well-being and environmental impacts. Hum. Ecol. Rev. 2009, 16, 114-123.

20. Dietz, T.; Rosa, E.A.; York, R. Environmentally efficient well-being: Is there a Kuznets curve. Appl. Geogr. 2012, 32, 21-28. [CrossRef]

21. Michalos, A.C. Encyclopedia of Quality of Life and Well-Being Research, 1st ed.; Springer: Dordrecht, The Netherlands, $2014 ;$ p. 7347.

22. Knight, K.W.; Rosa, E.A. The environmental efficiency of well-being: A cross-national analysis. Soc. Sci. Res. 2011, 40, 931-949. [CrossRef]

23. Zhang, S.; Zhu, D.J.; Shi, Q.H.; Cheng, M.W. Which countries are more ecologically efficient in improving human well-being? An application of the Index of Ecological Well-being Performance. Resour. Conserv. Recycl. 2018, 129, 112-119. [CrossRef]

24. Jorgenson, A.K. Economic development and the carbon intensity of human well-being. Nat. Clim. Chang. 2014, 4, 186-189. [CrossRef]

25. Bian, J.; Zhang, Y.; Shuai, C.Y.; Shen, L.Y.; Ren, H.; Wang, Y.P. Have cities effectively improved ecological well-being performance? Empirical analysis of 278 Chinese cities. J. Clean. Prod. 2020, 245, 118913. [CrossRef]

26. Long, L.J.; Wang, X. A study on Shanghai's ecological well-being performance. China Popul. Resour. Environ. 2017, 27, 84-92. (In Chinese)

27. Xiao, L.M.; Zhang, X.P. Spatio-temporal characteristics of coupling coordination between green innovation efficiency and ecological welfare performance under the concept of strong sustainability. J. Nat. Resour. 2019, 34, 312-324. (In Chinese)

28. Bian, J.; Ren, H.; Liu, P. Evaluation of urban ecological well-being performance in China: A case study of 30 provincial capital cities. J. Clean. Prod. 2020, 254, 120109. [CrossRef]

29. Tobler, W.R. A computer movie simulating urban growth in the Detroit region. Econ. Geogr. 1970, 46, 234-240. [CrossRef]

30. Anselin, L. Spatial effects in econometric practice in environmental and resource economics. Am. J. Agric. Econ. 2001, 83, 705-710. [CrossRef]

31. Guan, W.; Xu, S. Study of spatial patterns and spatial effects of energy eco-efficiency in China. J. Geogr. Sci. 2016, 26, 1362-1376. [CrossRef]

32. Wang, Z.; Sun, Y.; Yuan, Z.; Wang, B. Does energy efficiency have a spatial spill-over effect in China? Evidence from provinciallevel data. J. Clean. Prod. 2019, 241, 118258. [CrossRef]

33. Zhou, Y.; Kong, Y.; Zhang, T. The spatial and temporal evolution of provincial eco-efficiency in China based on SBM modified three-stage data envelopment analysis. Environ. Sci. Pollut. Res. Int. 2020, 27, 8557-8569. [CrossRef] [PubMed] 
34. Jin, F.J. Sustainable spatial welfare: The cornerstone for human beings' development. Geogr. Res. 2014, 33, 582-588. (In Chinese)

35. Li, J.; Luo, Y.; Wang, S.Y. Spatial effects of economic performance on the carbon intensity of human well-being: The environmental Kuznets curve in Chinese provinces. J. Clean. Prod. 2019, 233, 681-694. [CrossRef]

36. Li, C.Y.; Zhang, S.Q.; Zhang, W.; Liao, X.C. Measurement and influencing factors of inter-provincial ecological well-being performance in China. Sci. Geogr. Sin. 2019, 39, 1875-1883. (In Chinese)

37. Yao, L.; Yu, Z.N.; Wu, M.Y.; Ning, J.C.; Lv, T.G. The spatiotemporal evolution and trend prediction of ecological wellbeing performance in China. Land 2021, 10, 12. [CrossRef]

38. Zheng, D.F.; Wang, Y.Y.; Cao, Y.Q.; Wang, Y.H.; Hao, S.; Lv, L.T. Classification and spatiotemporal patterns of ecological well-being based on ecosystem services: Taking China's prefecture-level and above cities for example. Resour. Sci. 2020, 42, 1110-1122. (In Chinese) [CrossRef]

39. Zhu, D.J.; Zhang, S. Research on ecological welfare performance and deepening sustainable development. J. Tongji Univ. Soc. Sci. Sect. 2014, 25, 106-115. (In Chinese)

40. Du, H.B.; Huang, L.J.; Zhang, C.; He, J.J. Research on the regional differences decomposition and convergence mechanism of ecological well-being performance. Ecol. Econ. 2019, 35, 187-193. (In Chinese)

41. Andrew, K.; Jorgenson, A.K.; Dietz, T. Economic growth does not reduce the ecological intensity of human well-being. Sustain. Sci. 2015, 10, 149-156.

42. Jorgenson, A.K.; Alekseyko, A.; Giedraitis, V. Energy consumption, human well-being, and economic development in central and eastern European nations: A cautionary tale of sustainability. Energy Policy 2014, 66, 419-427. [CrossRef]

43. Zhu, D.J.; Zhang, S. Research on ecological welfare performance and its relationship with economic growth. China Popul. Resour. Environ. 2014, 24, 59-67. (In Chinese)

44. Sweidan, O.D. Economic performance and carbon intensity of human well-being: Empirical evidence from the MENA region. $J$ Environ. Plan. Manag. 2018, 61, 699-723. [CrossRef]

45. Engelbrecht, H.J. Nature capital, subjective well-being, and the new welfare economic of sustainability: Some evidence from cross-country regressions. Ecol. Econ. 2009, 69, 380-388. [CrossRef]

46. Long, R.; Zhang, Q.; Chen, H.; Wu, M.; Li, Q. Measurement of the energy intensity of human well-being and spatial econometric analysis of its influencing factors. Int. J. Environ. Res. Public Health 2020, 17, 357. [CrossRef]

47. Behjat, A.; Tarazkar, M.H. Investigating the factors affecting the ecological well-being performance in Iran from 1994 to 2014. Environ. Dev. Sustain. 2021. [CrossRef]

48. Liu, G.P. A study on China's energy welfare performance and its factorization: Based on G20 data. Inq. Into Econ. Issues 2017, 38, 24-30. (In Chinese)

49. Daly, H.E. A further critique of growth economics. Ecol. Econ. 2013, 88, 20-24. [CrossRef]

50. Charnes, A.; Cooper, W.W.; Rhodes, E. Measuring the efficiency of decision making units. Eur. J. Oper. Res. 1978, 2, 429-444. [CrossRef]

51. Tone, K. A slacks-based measure of efficiency in data envelopment analysis. Eur. J. Oper. Res. 2001, 130, 498-509. [CrossRef]

52. Qin, X.H.; Du, D.B.; Kwan, M.P. Spatial spillovers and value chain spillovers: Evaluating regional R\&D efficiency and its spillover effects in China. Scientometrics 2019, 119, 721-747.

53. Tone, K.; Tsutsui, M. Dynamic DEA: A slacks-based measure approach. Omega 2010, 38, 145-156. [CrossRef]

54. Cheng, G. Data Envelopment Analysis: Methods and MaxDEA Software; Intellectual Property Publishing House Co. Ltd.: Beijing, China, 2014.

55. Yan, X.; Cheng, C.C.; Yi, G.F.; Bai, J.C. Economic threshold effect of urbanization on energy consumption: Take the Yangtze River Economic Zone as an example. Econ. Geogr. 2019, 39, 73-81. (In Chinese)

56. Hansen, B.E. Threshold effects in non-dynamic panels: Estimation, testing and inference. J. Econom. 1999, 93, 345-368. [CrossRef]

57. Wang, Q.Y. Fixed-effect panel threshold model using Stata. Stata J. 2015, 15, 121-134. [CrossRef]

58. Chen, M.X.; Lu, D.D.; Zha, L.S. The comprehensive evaluation of China's urbanization and effects on resources and environment. J. Geogr. Sci. 2010, 20, 17-30. [CrossRef]

59. Rigina, O. Environmental impact assessment of the mining and concentration activities in the Kola Peninsula, Russia by multi-date remote sensing. Environ. Monit. Assess. 2002, 75, 11-31. [CrossRef] [PubMed]

60. Hohmann, A.; Albrecht, S.; Lindner, J.P.; Voringer, B.; Wehner, D.; Drechsler, K.; Leistner, P. Resource efficiency and environmental impact of fiber reinforced plastic processing technologies. Prod. Eng. 2018, 12, 405-417. [CrossRef]

61. Fang, F.Q.; Lv, W.H. Analysis of factors influencing the welfare level of Chinese urban residents based on Amartya Sen's competence method and structural equation model. Manag. World 2009, 25, 17-26. (In Chinese)

62. Jones, C.I.; Klenow, P.J. Beyond GDP? well-being across countries and time. Am. Econ. Rev. 2016, 106, 2426-2457. [CrossRef]

63. Hu, M.J.; Li, Z.J.; Ding, Z.S.; Zhou, N.X.; Qin, D.L.; Zhang, C. Urban ecological well-being intensity and driving mode based on three-dimensional well-being: Taking the Yangtze Delta as an example. J. Nat. Resour. 2021, 36, 327-341. (In Chinese)

64. UNDP (United Nations Development Program). China Human Development Report 2005: Development with Equity; UNDP: Beijing, China, 2005. 